\title{
On Intellectual Power of a Country
}

\author{
Xiulian $\mathrm{Liu}^{1, \mathrm{a}}$, Yao Li ${ }^{2, \mathrm{~b}^{*}}$ \\ ${ }^{1}$ Foreign Language School of Jianghan University,Wuhan,430056, China \\ ${ }^{2}$ Electromechanical Engineering School of Jianghan University,Wuhan,430056,China \\ aliuxiulian1000@sina.com \\ blylly111@sina.com
}

Keywords: Intellectual power; Think-tank; Role; Country; Construction

\begin{abstract}
In this paper, the concept of intellectual power is firstly presented at the national level. It assumes that the intellectual power mainly refers to the reflection of political wisdom, political acumen, strategic and tactical wisdom, leadership, decision-making power and comprehensive capability of a state, a government, a group, a team or an individual. Also, it indicates the methods to deal with various issues and the implementation capacity for decision-making. The intellectual power is embodied through the wisdom of human beings. The role and significance of intellectual power is discussed in this paper, which suggests that the effective use of intellectual power can make a country's hard power and soft power quickly and efficiently develop and prosper for a long time; but the improper use of intellectual power also makes the country face enormous risks and in great jeopardy. Intellectual power, hard power and soft power are interdependent, interacting and mutually independent. Finally, the proper use of the intellectual power and the measures to strengthen intellectual strength are explored.
\end{abstract}

\section{Introduction}

Joseph Nye, the professor of Harvard University, proposed the concept of soft power in his many papers in 1990. Joseph Nye pointed out that a country's comprehensive national power was not only composed of the hard power such as the economic, technological and military strength, but also the soft power like cultural and ideological appeal[1]. However, there is an essential power which the author named intellectual power. From the perspective of the national strategic decision-making, the intellectual power is also the main part of comprehensive strength. The intellectual power of a nation will be explored in this paper.

\section{The Concept of Intellectual Power}

The intellectual power refers to the reflection of political wisdom, political acumen, strategic and tactical wisdom, leadership, decision-making power and comprehensive capability of a state, a government, a group, a team or an individual. It is also the processing method in the face of a variety of issues and the implementation capacity for decision-making. The focus of the intellectual power is on people, who are the most important in this power. There is no intellectual power without people. But the intellectual power is not necessarily decided by the number of people, and it relies on the wisdom, experience, human capacity and the corresponding authority. Therefore, the strategy, judgments and recommendations that the intellectual tank makes are also decided by the authority of the decision-makers.

\section{The Role and Significance of the Intellectual Power}

Mao Zedong said, "The policy and strategy are the life of the Communist Party of China"[2]. What kind of policy to formulate and what kind of strategy to take depend on people's wisdom. The 
formulation of policy and strategy, if they could be done as Laozi pointed out in Tao Te Chip: The best virtue is like water, which benefits all things without any demands, it stays in the places others despise. And it is because of this that makes water so near to the way of the nature[3], is the culmination of wisdom. So, with the wisdom to make polices and to resolve conflicts, we can get twice the result with half the effort, as what was mentioned in Master Sun's Art of War : The wisest policy to do in a war is not to fight a hundred battles and win each, but to break the enemy's resistance without fighting. Thus, the top policy in war is to thwart the enemy's strategy. The second one is to disrupt his alliances through diplomatic means. The third one is to attack his army in the field. The worst one in all policies is to attack the walled cities [4]. This demonstrates the importance and role of a country's intellectual power.

Many kinds of complicated things and issues can be effectively solved if intellectual power is used properly. Many historical events can illustrate the role of intellectual power for a country's future from home and abroad.

Even if a country has a strong hard and soft power, the country will face or be indulged in a huge risk if it lacks of intellectual power or uses intellectual power improperly. In 2003, the United Kingdom launched an invasion into Iraq and overthrew Saddam Hussein's regime with strong hard and soft power. However, due to the improper use of intellectual power, there were something wrong with their policy and decision. So, Iraq has been in turmoil and the lives and property of the people cannot be protected. The U. S. has not achieved its goal. This clearly indicates that the American strategic decision of invasion into Iraq was a failure. Conversely, the proper use of intellectual power can promote and develop a country for a long time. The policy of our reform and opening-up, conducted by Mr. Deng Xiaoping shows the proper use of super political wisdom, which makes China become more thriving and prosperous. For example, our GDP has reached the second in the world within 40 years.

Strengthening the construction and effective use of the intellectual power can make the national policies, regulations and planning more scientific, systematic and rational, which is conductive to the country's long-term stability and the establishment of a harmonious society.

Proper use of the intellectual power can be not only helpful in seeking common ground on major issues, reserving differences on minor ones to achieve peaceful coexistence between countries, and handling all types of complex issues effectively, but also in developing a peaceful world.

Therefore, strengthening the intellectual power of the construction has important theoretical and practical significance not only in improving the management level, leadership, decision-making ability, and the whole quality of the nation of a country, a government, and decision-makers, but also helping handle the country's internal and external conflicts, promoting the development of the national economy, building a harmonious society and further enhancing both hard and soft power. We can say that intellectual power of a country is an important pillar of hard and soft power development.

\section{The Dialectical Relationship among the Intellectual Power, Hard Power and Soft Power}

The relationships among intellectual power, hard power and soft power are interdependent, interactive and mutually independent.

Hard power refers to a visible and tangible force, which is the material basis of national construction and development. It is the tangible carrier of soft power. Solid hard power can contribute to the extension of the country's soft power, while hard power lays the material foundation for the effective use of intellectual power. The report from Xinhua net says that the GDP of our country has reached the second place of the world, which is a sign of hard power[5]. Only on the basis of a strong economy, can we create Confucius Institutes abroad to make more people understand our culture and policies better, and also to promote the extension and expansion of soft power objectively. 
Soft power, as an important part of overall national power, refers to the invisible influence which is embodied from the attraction of political systems and policies, the appeal of cultural value and the affinity of the national image. It profoundly affects people on the issues of international relations and our country's role in international affairs. Soft power is the invisible extension of hard power, which can contribute to improving the quality of the people, strengthening the recognition and understanding of the principles, and policies of our country, promoting China's economic construction and further enhancing hard power. Soft power provides the intangible basis of culture and system for the effective use of intellectual power. It also provides historical references for the use of intellectual power.

Intellectual power is neither a material wealth like the hard power, nor an intangible asset of culture and system like the soft power. Intellectual power is, sometimes, a strategy, an idea, a policy, a plan, a vision and even a word, which is likely to be a great wisdom. This wisdom is better than the wealth and a powerful army. Deng Xiaoping said, "Development is the only way to go" [6]. He summed up the practical experience of the human and China's development and made the scientific conclusion. Development itself is a scientific concept containing a rich connotation. People's conception has changed from "increase" to "develop", which is a historic turning point. This strategic thinking effectively reflects great wisdom.

Intellectual power is the performance of human wisdom and it is immaterial. It refers to people's thinking activities. The mighty of intellectual power does not depend on the number of the people. It not only refers to the great wisdom and great thinking on macro-level, but also a concrete analysis of each specific issue on micro-level. Comrade Mao Zedong raised the policy in the period of land revolution war: To win the revolutionaries by encircling the cities from the rural areas [7]. This reflects the farsighted political and strategic wisdom of Comrade Mao Zedong. It is the practice of both great wisdom on macro-level and a concrete analysis of specific issues on micro-level of intellectual power.

Based on the hard and soft power, intellectual power can access on all kinds of things and make strategic policies to optimize the country's hard power and soft power. Intellectual power not only conducts hard power and its scale, but also promotes the extension of soft power to enhance the development of hard power and soft power. However, inadequate or inappropriate use of intellectual power also weakens the existing hard power and soft power. Intellectual power can be independent of hard power to play an important role in the particular case. In the early 1950s, China was newly-founded. The national economy's output was not high, and quite few countries had diplomatic relations with China. At that time, our hard power or soft power were very weak. Based on this kind of hard and soft power, Chinese did not have any of the advantages of participation in the war to resist the US aggression and aid Korea. However, president Mao Zedong and his administration demonstrated a strong intellectual power and made resolute decision to aid Korea, which ultimately forced the United Nation forces led by the US to give the way to armistice. If we had not the war to resist the US and aid Korea, the Yalu River in our country would be an American military base today, and we would not be in a peaceful environment.

\section{The Effective Signs of Intellectual Power}

The effective wisdom of intellectual power should be reflected in the fields of foresight, systematicness, principle and flexibility.

Foresight, for a country, is to foresee how it can develop sustainably, steadily and healthily. Based on the hard and soft power, appropriate strategic development planning and goals which will be achieved in the future are set up such as the five-year plan and long-term development plan, which are the specific manifestation of intellectual power. The formulation and implementation of these goals will require the use of intellectual power to advance ideas. Foresight is one of the effective signs of intellectual power. 
Systematicness means when formulate national policies and strategic planning, we must not only consider the overall situation, but also all concrete aspects of our country's development. Otherwise, we might attend to one thing and lose another. So, intellectual power also exhibits systematic requirements. In the military forum, some experts always compare the merits and performance of military equipments, and believe that the weapons decide everything. However, it is the intellectual power that supports the hard power, namely, the use of wisdom. If weapon was everything on the military, we would not have the war to resist the US and aid Korea and the war of Zhenbao Island, and We would be scared by enemy's hard power. Thus, policy formulation should be taken into account systematically and comprehensively in order to consider the issue decisively and avoid its disadvantages and advocate advantages.

Principle emphasizes that the formulations of laws, regulations, policies, requirements and systems must be based on their own principles. We advocate Five Basic Principles of Peace to deal with the relations with other countries which are the basic principles to develop relations with other countries. Flexibility should be also embedded in the practice of the intellectual power. Although we advocate the Five Base Principles to deal with other countries, we should practice flexibly, because of the different ideologies and political systems of different countries.

Scientific development requires that the think tanks should formulate policies and strategies layout scientifically for national development. Premier Li Keqiang pointed out at the meeting of the academy that "we are fully qualified and capable of walking across the middle-income trap and continuing to maintain high growth in the longer period on the basis of rapid growth in the past thirty years"[8].This shows that when the experts formulate policies, the policy should be scientific in order to play a sustainable role of guiding.

The realistic and feasible role tells us that we must pay more attention to the operability when dealing with various problems and formulating policies, strategies and methods. Otherwise, it was empty talk. Therefore, practice and operation can also indicate the effectiveness of intellectual power. Deng Xiaoping, regarded as the chief architect, implemented the concept of peaceful reunification and one country two systems for the return of Hong Kong, which is based on the theory of dialectical materialism and historical materialism. It is the result for the CPC to free minds and seek truth from facts. It is the specific practice of combining the universal truth of Maxism and the Taiwan issue, the Hong Kong issue and the Macao issue. This thinking provides a new vision, which is a creative decision in solving historical problems. They are very significant in both theory and reality.

Authority means that the recommendations and strategies that think tank makes are finally determined by the authority, which showed the authority of intellectual power.

Willpower indicates that wisdom policies and strategies need to be implemented by the decisive willpower of the decision-makers. Otherwise the wise idea, policy of idea will be empty.

The proper use of intellectual power can make national construction have great achievements. The process of deciding, planning, organizing and manufacturing of China's first atomic bomb and hydrogen bomb fully illustrated the use of wisdom such as the resolution decision and authority willpower. This wise decision has been exerting a significant impact.

\section{The Construction of the Intellectual Power}

Our long history, culture, allusion and famous events lay a solid foundation for us to improve intellectual power. For example, "Thirty-Six Stratagems", "History as a Mirror" and "The Art of War" are the concrete manifestation of intellectual power. That is why we should learn from history. The construction of intellectual power is carried out according to "people orientation", because the body of the intellectual power focuses on talents.

Valuing Talents. The focus of the intellectual power is on talents. Therefore, our country should value knowledge and talents. Of all things human is the most valuable. As long as there are talents, whatever miracles can be made. This is a prerequisite for the development of intellectual power. 
Initiating Vigorously Various Types of Education. Education is one of the most basic and important measures to improve the intellectual power of a country. It is the most core competitiveness for a country in the world. There is no intellectual power without education, so education is the most important means for a country to enhance their intellectual power. China has more than 1.3 billion people, but it has only about 2500 colleges and universities of various types, which cannot meet the needs of the people for education[9]. Therefore, we should also develop our education and promote the quality improvement of the whole nation.

Enhancing the Construction of Think Tanks and Consulting Firm. The think tank mentioned here is also called as "mind tank", or "brain truster". It is a public research institution composed of multidisciplinary experts to provide ideas in dealing with the problems of society, economy, technology, military, diplomacy and also, provide the best theories, strategies, methods, ideas and etc.. The quality and the number of think tanks and consulting firms can mainly embody the intellectual power of a country. Although the number of think-tanks and consulting firms in our country ranks as the second in the world, our think tanks do not enjoy advantage when compared to those of the developed countries[10]. And these think tanks and consulting firms are mainly concentrated in the universities. Therefore, to strengthen the construction of the think-tank and consulting firm is a strong measure to consolidate the intellectual power.

Improving Personal Quality. National policies, laws, regulations and policies are formulated by people, so personal quality is very crucial. It needs individual innovative thinking and innovation. For an individual, he should be loyal for his country and love his people. He should be not only erudite, understand reality, but also be familiar with national policies, institutions and the world situation. Also, he should think systemically and innovatively and deal with the problems comprehensively and systematically. At the same time, the people must have strong characters, with which the people are likely to come up with thinking sparks.

\section{Conclusion}

The intellectual power of a country was briefly discussed above. Wisdom is a helpful in developing a strategy of a country. In a sense, it may be more important than hard power and soft power. From a micro-view, it can boom a business, in turn, and it may also break a business. From a macro-view, it can help a government play a greater role, and may also make the government run inefficiently and incompetently. It can make a country grow sustainably and people live a happy life. And it can also cause a country to stagnate and people live a hard life. Therefore, the construction and use of intellectual power is critical. It should attract the attention of a state or a government, especially in the current complicated domestic and international environment.

\section{References :}

(1) H. Liu(trans.), Is the United States Destined to Lead the World? Renmin University of China Press, 2012. (In Chinese)

(2) Selected Works of Mao Zedong,Vol. IV(1960)p.1296.People's Publishing House.(In Chinese)

(3) Tao Te Chip, Jindun Publishing House, 2009. (In Chinese)

(4) The Art of War, Ocean Press, 2007. (In Chinese)

(5) Information on http://news. Xinhuanet. Com/fortune/2012-06/03/c-11212158/.htm (In Chinese)

(6) The Literature Editorial Board of the CPC Central Committee, Selected Works of Deng Xiaoping ,Vol. III(1993) People's Publishing House.(In Chinese)

(7) Selected Works of Mao Zedong,Vol. I(1991). People's Publishing House. (In Chinese) 
(8) K.Q. Li, The Economic Situation Report at the Academicians Assembly, People's Daily (Overseas Edition), June 11,2014. (In Chinese)

(9) Information on http://learning. Sohu.com/20140820/n403602703.shtml (In Chinese)

(10) T.T. Rong, The Five Suggestions to Construct New Types of Think Tanks with Chinese Characteristics. Globalization,2014(4). 